\title{
Enteropathogenic Escherichia coli enteritis: evaluation of the gnotobiotic piglet as a model of human infection
}

\author{
S TZIPORI, R M ROBINS-BROWNE, GENA GONIS, JANE HAYES, \\ MAREE WITHERS, AND ELINOR MCCARTNEY
}

From the Attwood Institute for Veterinary Research, Westmeadows; Department of Microbiology, University of Melbourne, Parkville, Victoria 3052, Australia

SUMmARY The pathogenicity of classical enteropathogenic Escherichia coli strains of human origin was investigated in gnotobiotic piglets. One to two day old piglets in groups of four were infected perorally with approximately $10^{8}$ colony forming units of one of eight enteropathogenic $E$ coli strains or a non-pathogenic control strain. Animals were necropsied 24 or 48 hours after infection and their intestines were subjected to histological examination, quantitative bacterial culture and estimation of lactase activity. Four enteropathogenic $E$ coli strains caused mild to moderate diarrhoea in nine of the 16 piglets inoculated with them. Piglets given two of these strains later became moribund. One enteropathogenic $E$ coli strain caused a severe illness unaccompanied by diarrhoea. Inflammation of the intestinal mucosa occurred with all eight enteropathogenic $E$ coli strains, but not with the control strain. Pathological changes were most pronounced in the distal ileum and colon and adherent bacteria were seen on the surface of the inflamed mucosa. The extent of the inflammatory response in infected piglets for the most part paralleled the severity of the clinical signs, the degree of bacterial colonisation and the reduction in lactase activity. Electron microscopic examination of tissue from piglets infected with three different strains showed that bacterial adherence to the apical plasma membrane of epithelial cells was accompanied by distinctive ultrastructural changes. These included degeneration of the microvillous brush border, together with cupping and pedestal formation of the plasma membrane at sites of bacterial attachment. The same changes have been seen in naturally occuring enteropathogenic $E$ coli diarrhoea in humans and rabbits. The combined clinical and pathological findings indicate that the neonatal gnotobiotic piglet is a suitable model of infection with enteropathogenic $E$ coli.

Escherichia coli is both the predominant member of the normal aerobic colonic flora and a prominent cause of gastroenteritis. ${ }^{1}$ Strains of $E$ coli that cause diarrhoea are divided into three categories according to their pathogenic mechanisms. ${ }^{12}$ The pathogenicity of enterotoxigenic $E$ coli resides in their ability to colonise the surface of the small intestine and to produce heat-labile and/or heat-stable enterotoxins. ${ }^{2}$ Enteroinvasive $E$ coli, by contrast, penetrate and proliferate within the large bowel epithelium. ${ }^{12}$

A third category of diarrhoeagenic $E$ coli

Address for correspondence: Dr R M Robins-Browne, Department of Microbiology. University of Melbourne, Parkville, Victoria, 3052. Australia.

Received for publication 19 July 1984 comprises bacteria that attach intimately to the intestinal epithelium and disrupt the microvillous brush border of intestinal epithelial cells. These bacteria, which Moon et $a^{3}$ have termed attaching effacing $E$ coli, appear to include the traditional or 'classical' enteropathogenic $E$ coli $^{4}$ that have been responsible for numerous nosocomial outbreaks of severe infantile diarrhoea ${ }^{14}$ and that, in some parts of the world, play an important role in sporadic diarrhoea of infants and young children. ${ }^{5}$

The underlying mechanism of enteropathogenic $E$ coli-induced diarrhoea is not clear. Enteropathogenic $E$ coli possess no well defined virulence factors. They do not produce conventional enterotoxins ${ }^{6}$ or invade the intestinal mucosa, and generally they are identified by serotyping alone. ${ }^{7}$ An animal model would not 
only facilitate investigation of the pathogenic mechanisms of enteropathogenic $E$ coli diarrhoea, but could also be used to examine methods of identifying enteropathogenic $E$ coli more convenient and reliable than serotyping.

Pigs have previously served as models of diarrhoea caused by various bacteria, viruses, and protozoa, ${ }^{8-10}$ and in view of recent observations that piglets may also be susceptible to infection with enteropathogenic $E$ coli, ${ }^{311}$ we inoculated neonatal gnotobiotic piglets with several enteropathogenic $E$ coli strains of human origin and determined their clinicopathological response. Our findings are reported in this paper.

\section{Methods}

BACTERIA

Seven enteropathogenic $E$ coli strains isolated during outbreaks of infantile diarrhoea and one from a sporadic case were used ${ }^{1213}$ (Table 1). A non-pathogenic $E$ coli strain, recovered from a healthy pig, served as a control. All strains were unreactive in conventional assays of $E$ coli pathogenicity, including tests for invasive capacity and for the production of enterotoxins and colonisation factor antigens. Two of the enteropathogenic $E$ coli strains were previously shown to produce diarrhoea in adult volunteers. ${ }^{14}$

Bacteria were maintained freeze dried or in $30 \%$ glycerol at $-20^{\circ} \mathrm{C}$. Before inoculation of experimental animals, test strains were cultivated on $5 \%$ sheep blood agar overnight at $37^{\circ} \mathrm{C}$ and harvested in sterile physiological saline.

\section{EXPERIMENTAL ANIMALS}

Thirty-six gnotobiotic piglets were derived as described previously ${ }^{15}$ and maintained in groups of four in sterile plastic containers. They were bottle fed five or six times daily a total of 200 to $250 \mathrm{ml}$ reconstituted evaporated cow's milk. For the experimental challenge, one to two day old piglets in each group were inoculated perorally with between $10^{8}$ and $2 \times 10^{8}$ colony forming units of a test strain. Twenty four or 48 hours later, two piglets in each group were given a lethal intracardiac dose of sodium pentobarbitone and necropsied.

NECROPSY PROCEDURE AND TISSUE EXAMINATION Segments from the proximal, mid and distal small intestine as well as one each from the caecum and colon were obtained and fixed in neutral buffered formalin. Sections were stained with haematoxylin and eosin, and by the peroxidase- antiperoxidase (PAP) technique ${ }^{16}$ using specific $E$ coli $\mathrm{O}$-antisera. Pathological changes in haematoxylin- and eosin-stained sections were graded on a scale of to +++ (Table 2). PAP-stained sections were used to estimate the extent of bacterial attachment (Table 2).

Tissue for transmission electron microscopy was fixed in $2.5 \%$ gluteraldehyde, postfixed in $2 \%$ aqueous osmium tetroxide and stained en bloc in $2 \%$ uranyl acetate in $70 \%$ acetone.

The proximal, mid and distal small intestine were also sampled for bacterial counts and for estimation of lactase activity. For bacterial counts, serial 10-fold dilutions of homogenised gut contents and mucosal scrapings were prepared in sterile physiological saline, plated on paired $5 \%$ sheep blood and MacConkey agar plates, and incubated overnight at $37^{\circ} \mathrm{C}$. Lactase activity in homogenised mucosa was determined by the method of Dahlquist. ${ }^{17}$

\section{Results}

CLINICAL FINDINGS

Piglets infected with enteropathogenic $E$ coli

Table 1 Escherichia coli strains used in this study

\begin{tabular}{|c|c|c|c|c|c|}
\hline Strain & Designation & Serotype & Origin & $\begin{array}{l}\text { Pathogenicity } \\
\text { for adult } \\
\text { volunteers }\end{array}$ & References \\
\hline E508/69 & EPEC & 0114:H2 & Manchester, England & NT & 12 \\
\hline $\mathrm{E} 2347 / 69$ & EPEC & 0114:H2 & Taunton, England & NT & 12 \\
\hline UR & EPEC & 0125ac:H? & Chapel Hill, NC, USA & NT & 13 \\
\hline E63/68 & EPEC & 0128:H2 & Teesside, England & NT & 12 \\
\hline E74/68 & EPEC & 0128:H2 & Teesside, England & - & 12,14 \\
\hline$E 2348 / 69$ & EPEC & 0127:H6 & Taunton, England & + & 12,14 \\
\hline $\mathrm{E} 2381 / 70$ & EPEC & 0142:H6 & Glasgow, Scotland & NT & 12 \\
\hline $\mathrm{E} 851 / 71$ & EPEC & 0142:H6 & Glasgow, Scotland & + & 12,14 \\
\hline P3175 & Normal flora & $0 ?: \mathrm{H} 32$ & Bendigo, Australia & NT & \\
\hline
\end{tabular}

NT $=$ Not tested. EPEC $=$ enteropathogenic $E$ Coli. 
Table 2 Major clinical and histopathological findings in pairs of gnotobiotic piglets inoculated with an enteropathogenic Escherichia coli strain of human origin or with non-pathogenic pig E coli

\begin{tabular}{|c|c|c|c|c|c|c|c|c|}
\hline \multirow[b]{3}{*}{$\begin{array}{l}\text { E coli } \\
\text { strain }\end{array}$} & \multicolumn{4}{|c|}{24 hours after inoculation } & \multicolumn{4}{|c|}{48 hours after inoculation } \\
\hline & \multirow[b]{2}{*}{$\begin{array}{l}\text { Clinical } \\
\text { signs }\end{array}$} & \multicolumn{3}{|c|}{ Histopathologı** } & \multirow[b]{2}{*}{$\begin{array}{l}\text { Clinical } \\
\text { signs }\end{array}$} & \multicolumn{3}{|c|}{ Histopathology } \\
\hline & & $\begin{array}{l}\text { Proximal } \\
\text { small } \\
\text { intestine }\end{array}$ & $\begin{array}{l}\text { Distal } \\
\text { small } \\
\text { intestine }\end{array}$ & $\begin{array}{l}\text { Large } \\
\text { intestine }\end{array}$ & & $\begin{array}{l}\text { Proximal } \\
\text { small } \\
\text { intestine }\end{array}$ & $\begin{array}{l}\text { Distal } \\
\text { small } \\
\text { intestine }\end{array}$ & $\begin{array}{l}\text { Large } \\
\text { intestine }\end{array}$ \\
\hline E508/69 & Normal & $+1+$ & $++1++$ & $++/++$ & Moribund & $++1+$ & $+++1+$ & $++1++$ \\
\hline $\mathrm{E} 2347 / 69$ & Normal & $+1-$ & $++/+$ & $++1++$ & Normal & $-1-$ & $+1+$ & $++1++$ \\
\hline UR & Normal/Moribund & $++1+$ & $++1+$ & $++1++$ & Diarrhoea & $+1-$ & $++1+$ & $++1++$ \\
\hline E63/68 & Normal & $-1-$ & $+1-$ & $-/+$ & Normal & $+1-$ & $+1+$ & $-1+$ \\
\hline E74/68 & Normal & $-1-$ & $-1-$ & $+1+$ & Normal & $+1-$ & $+1+$ & $+1+$ \\
\hline $\mathrm{E} 2348 / 69$ & Normal & $+1-$ & $+1+$ & $+++/+++$ & Diarrhoea & $+1-$ & $++/+$ & $+++1++$ \\
\hline E2381/70 & Diarrhoea & $+1-$ & $+1+$ & $+++1+++$ & Moribund & $++1-$ & $++1+++$ & $+++1+++$ \\
\hline E851/71 & Diarrhoea & $+1+$ & $+++1++$ & $+++1++t$ & Diarrhoea & $+1-$ & $+++1+++$ & $+t+t$ \\
\hline P3175 & Normal & $-1-$ & $-1-$ & $-1-$ & Normal & $-1-$ & $-1-$ & $-1-$ \\
\hline
\end{tabular}

* Each result is the combined findings for 2 piglets expressed semiquantitatively as:

mucosal changes/bacterial attachinent, where:

- represents no change; + scattered submucosal inflammatory cell infiltrate; ++ scattered submucosal inflammation, mild congestion and submucosal oedema; +++ extensive inflammatory cell infiltrate thoughout mucosa, intense congestion and submucosal oedema; and

- represents no attachment: + few scattered foci of attachment ++ extensive focal attachment +++ heavy continuous attachment

displayed widely differing clinical responses, ranging from no apparent effect, through diarrhoea, to severe generalised illness (Table 2). With the exception of $E$ coli UR, however, each bacterial strain elicited a reproducible clinical response in piglets.

Twenty four hours after inoculation, increased frequency of discharge and fluid contents in the faeces, interpreted as mild diarrhoea, was observed in three of four piglets inoculated with enteropathogenic $E$ coli $\mathrm{E} 851 / 71$ and in two of four piglets given strain E2381/70. In contrast, piglets inoculated with other strains, including the non-pathogenic control strain, produced semi-solid or pasty yellow faeces. One piglet inoculated with enteropathogenic $E$ coli UR became moribund within 20 hours, and another, given enteropathogenic $E$ coli E63/68, died of causes unrelated to infection.

Forty eight hours after inoculation, the two remaining piglets inoculated with strains E508/69 and E2381/70 were moribund, while mild diarrhoea was observed in both piglets inoculated with enteropathogenic $E$ coli $\mathrm{E} 851 / 71$ and UR, and in one piglet given strain E2348/69. The illness caused by enteropathogenic $E$ coli E508/69, although severe, was not accompanied by diarrhoea. The clinical findings are summarised in Table 2.

NECROPSY FINDINGS

Necropsy findings were unremarkable. The intestine of a few piglets, notably those infected with enteropathogenic $E$ coli 508/69, E2348/69, E2381/70, and E851/71 contained liquid faeces, but otherwise all appeared grossly normal.

\section{HISTOPATHOLOGY}

Despite the range of clinical responses of piglets to the different enteropathogenic $E$ coli strains, the pathological changes resulting from infection were broadly similar, differing only in severity and extent. All animals that received enteropathogenic $E$ coli, but not those infected with the normal flora strain, showed focal inflammation of the lamina propria of the large and small intestine. Pathological changes occurred throughout the intestine, but were most pronounced in the distal ileum and colon.

In general, the severity and extent of the pathological changes corresponded to the duration of infection and the clinical presentation. Thus, in piglets infected with enteropathogenic $E$ coli that produced no ill effects - for example, strains E2347/69 and E74/68, histological changes were restricted to widely scattered foci of submucosal inflammation (Figs. 1a, and 2a, Table 2). In contrast, enteropathogenic $E$ coli that caused clinical disease - for example, strains E851/71, E2381/70, and E508/69, elicited extensive mucosal and submucosal polymorphonuclear leukocytic infiltration, hyperaemia and oedema (Figs. 1b, c and $2 b, c)$. The consistency of the changes induced 

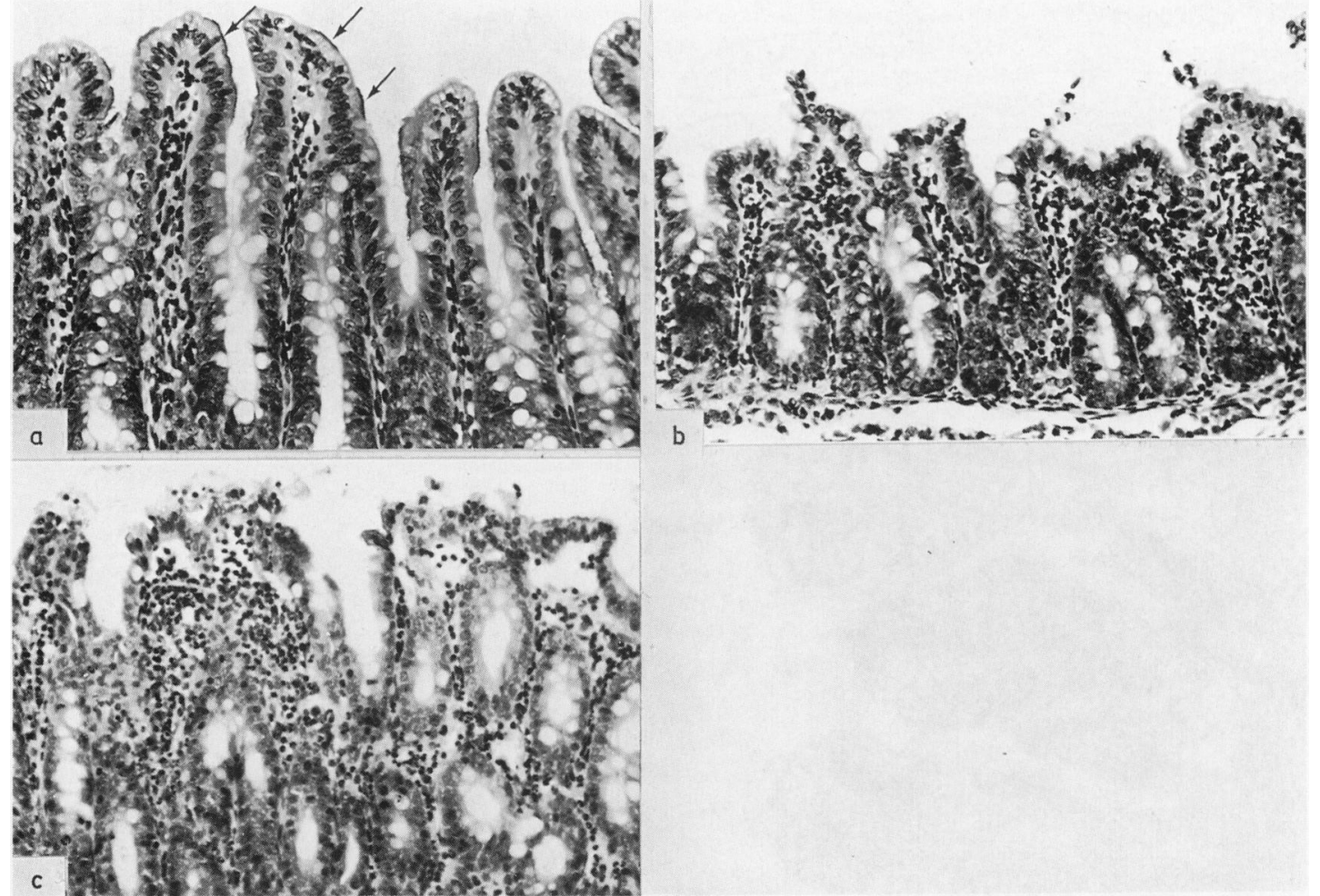

Fig. 1 Light micrographs of the large bowel of gnotobiotic piglets 24 hours after inoculation with different strains of human enteropathogenic Escherichia coli showing variable degrees of mucosal changes. (a) Strain E2347/69 had no effect on the integrity of the epithelial lining, and the lamina propria is only mildly infiltrated with inflammatory cells. Note bacterial clumps intimately associated with the epithelium (arrows) $(\times 200$ original magnification). (b) Strain E851/71 induced moderate changes. The epithelium is irregular, slightly flattened and sloughed at the villous tips. The lamina propria is infiltrated with inflammatory cells $(\times 200$ original magnification $)$. (c) E coli E2381/70 caused much more severe changes. The epithelium is flat or absent with focal vacuolation and nuclear stratification. Cellular infiltration in the mucosa can be seen exuding into the lumen through ulcerated villi $(\times 192$ original magnification $)$. Crypt cells in all three sections appear normal. Haematoxylin-eosin.

by each strain made it possible to rank the bacteria in decreasing order of pathogenicity as follows: $\mathrm{E} 508 / 69>\mathrm{E} 2381 / 70>\mathrm{E} 851 / 71>\mathrm{E} 2348 / 69>$ UR $>$ E2347/69 > E63/68 and E74/68.

The extent of bacterial colonisation observed in PAP-stained sections paralleled the histopathological findings. Enteropathogenic $E$ coli numbers appeared greatest in those piglets that showed the most pronounced morphological changes and in those regions of the intestine that were most severely affected (Table 2). This observation was confirmed by the bacterial counts in the small intestine, which revealed an increase in bacterial numbers from the proximal to the distal small intestine.

ELECTRON MICROSCOPY

Electron microscopic examination of sections of large and small intestine from piglets given strains E2381/70, E851/71, and E2347/69 showed that these bacteria induced similar, distinctive lesions of the mucosa, which varied only in extent and severity in keeping with the light microscopic findings. In general, lesions with adherent bacteria were multifocal in the ileum and more diffuse in the colon, but otherwise were similar throughout the intestine.

The brush border and apical cytoplasm of infected epithelial cells showed varying degrees of degeneration. At sites of bacterial attachment, microvilli were absent; between attachment sites they were elongated, shortened or absent (Fig. 3). Increased density of the terminal web directly beneath attached bacteria was frequently seen (Fig. 3). The plasma membrane was cupped or raised in the form of pedestals beneath attached 


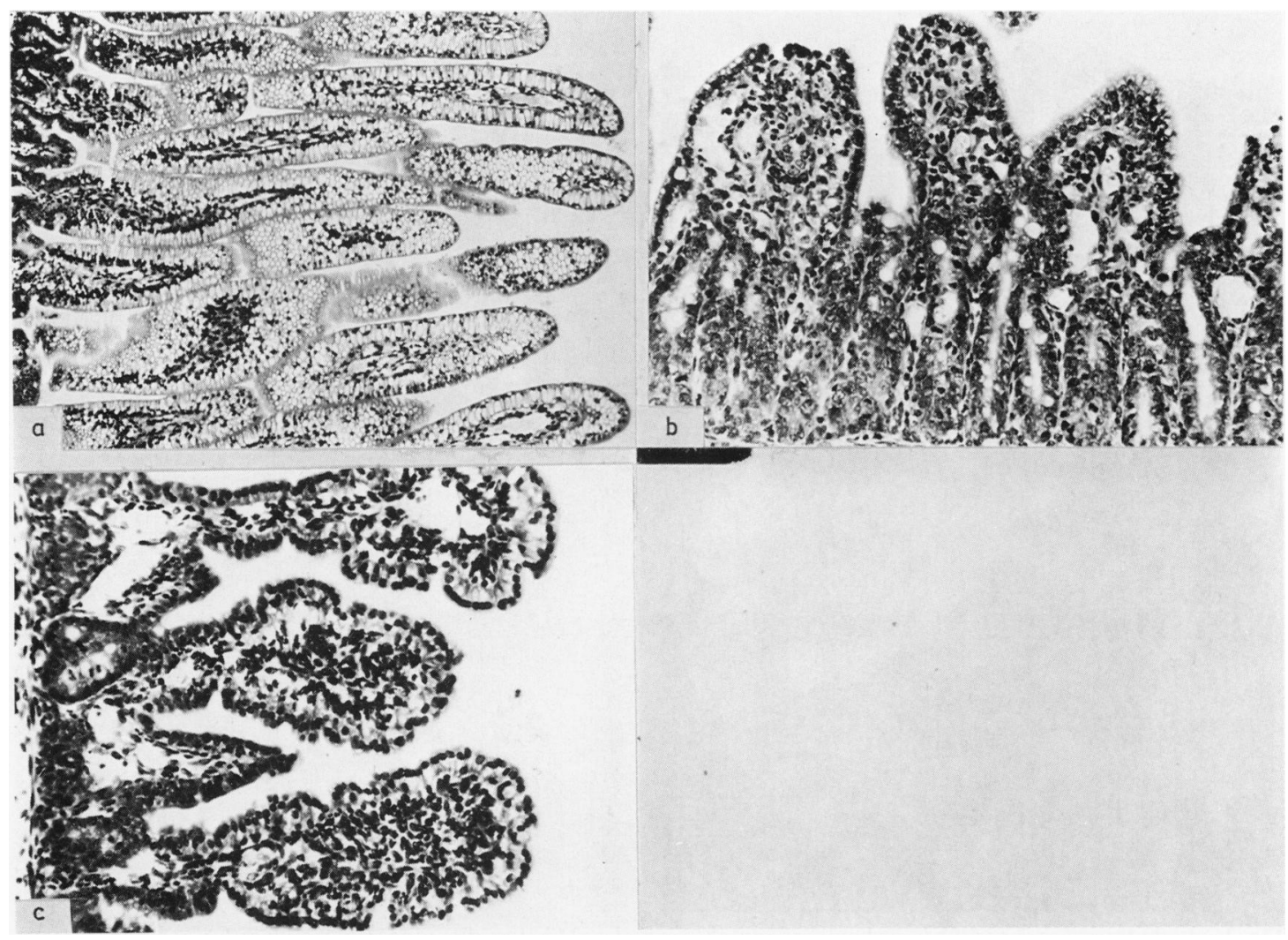

Fig. 2 Light micrographs of the small intestine of gnotobiotic piglets 48 hours after inoculation with different strains of human enteropathogenic Escherichia coli showing mucosal changes of differing severity. (a) and (b) show the contrasting effect of strains E74/68 and E851/71 respectively on the mucosa in the midileum. (a) E coli E74/68 induced no apparent changes. Extensive vacuolation of enterocytes is normmal ( $\times 85$ original magnification). (b) By contrast $\mathrm{E}$ coli E851/71 caused marked shortening of villi and lengthening of crypts. Villi are heavily infiltrated with inflammatory cells, and absorptive cells are flat or absent at some villous tips ( $\times 200$ original magnification). (c) Strain E508/69 induced mucosal changes throughout the small intestine. This section through the proximal jejenum shows swollen villi heavily infiltrated with inflammatory cells. The tissue appears extremely friable ( $\times 200$ original magnification). Haematoxylin-eosin.

bacteria (Fig. 4). Apart from brush border degeneration, damage to the epithelium was evidenced by loss of apical cytoplasm (Fig. 4) and extrusion of severely affected cells.

Occasional absorptive cells containing bacteria within membrane-bound vacuoles were observed in the ileum and colon (Fig. 5). Bacteria were not seen to penetrate between epithelial cells. Some bacteria were seen in the cytoplasm of phagocytes in the intestinal lumen, but not in those in the lamina propria.

\section{LACTASE ACTIVITY}

Alterations to small intestinal integrity and function, as evidenced by reduced lactase activity, corresponded with the extent and severity of the morphological changes. In piglets inoculated with the more virulent enteropathogenic $E$ coli strains, lactase concentrations in the proximal and mid small intestine were generally less than half those in piglets given enteropathogenic $E$ coli strains of reduced pathogenicity or the normal flora strain (Spearman's rank order correlation coefficient $[\rho]$ $=-0.70$ and -0.59 for the jejunum and mid ileum respectively; $\mathrm{p}<0.05)$. In the terminal ileum, where lactase concentrations are physiologically low, no significant correlation between histological findings and lactase activity was found $(\rho=-0 \cdot 32$; $\mathrm{p}>0 \cdot 1)$.

\section{Discussion}

Early descriptions of enteropathogenic $E$ coliinduced changes in experimental animals are 


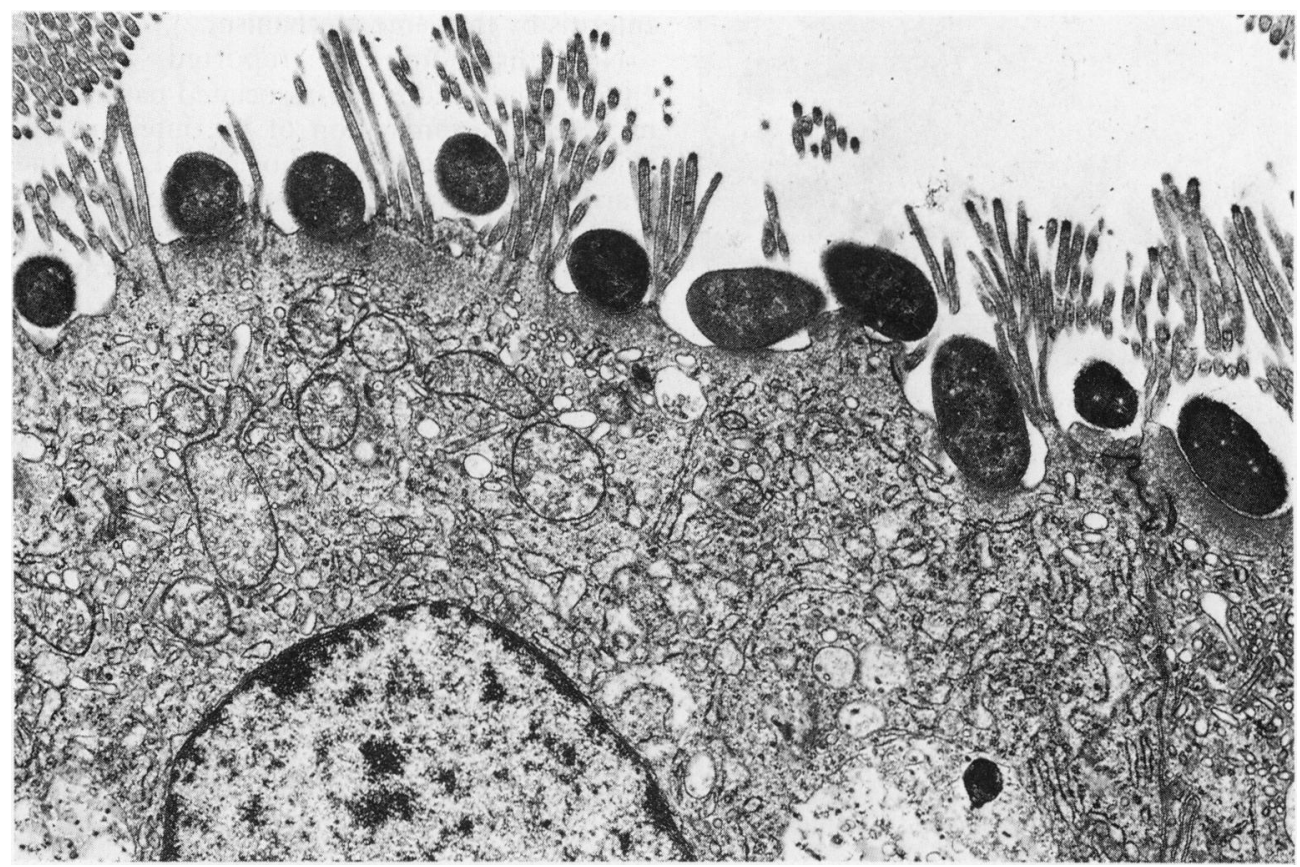

Fig. 3 Electron micrograph showing bacteria adhering to the apical surface of enterocytes in the midileum. Note the elongated microvilli between bacteria, and the absence of microvilli and increased terminal web density at sites of bacterial attachment. $(\times 10000$ original magnification $)$.

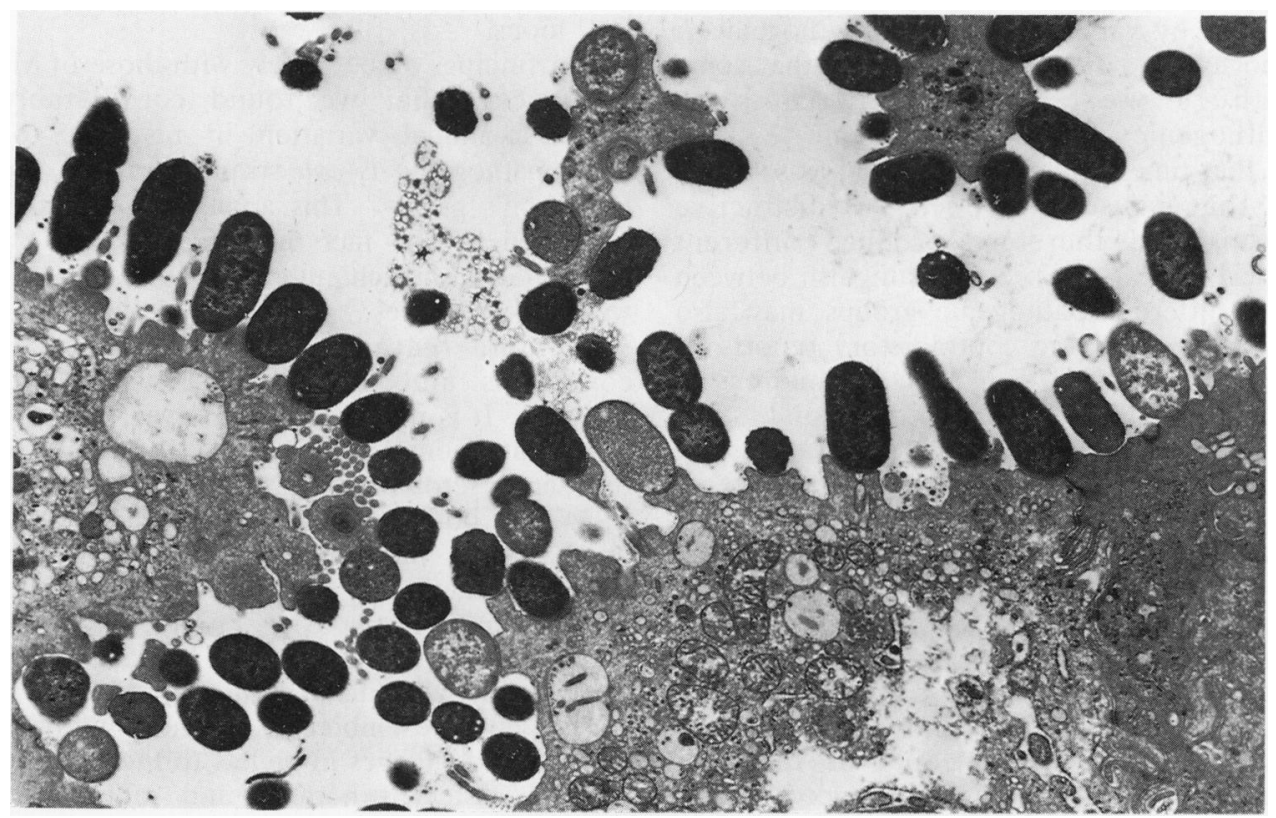

Fig. 4 Electron micrograph of the colon showing bacteria adhering to surface epithelial cells and to cellular material shed into the lumen. There is some loss of apical cytoplasm and disruption of cellular organelles $(\times 7500$ original magnification). 


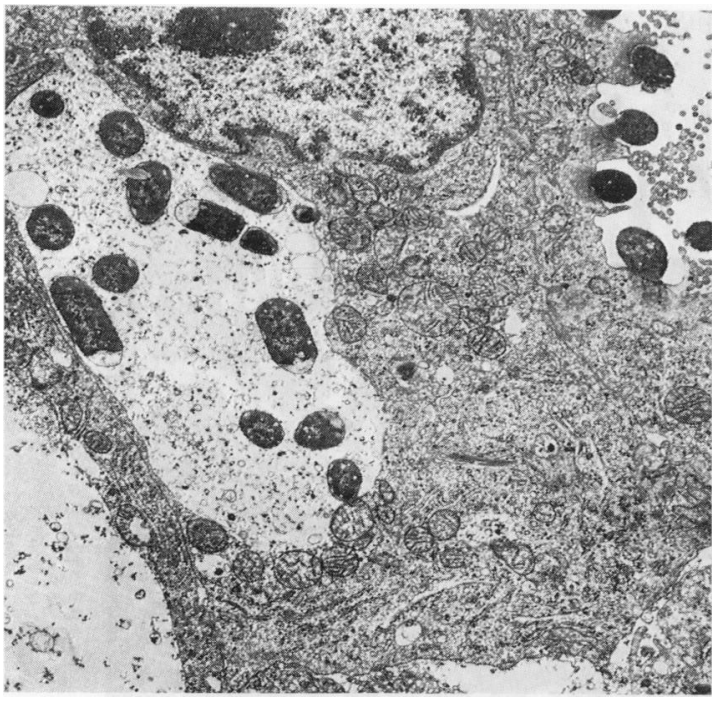

Fig. 5 Electron micrograph of the ileum showing bacteria within a membrane bound vacuole in the cytoplasm of an absorptive cell. The separation of bacterial cell contents from the cell wall may have occurred during processing $(\times 6000$ original magnification $)$

conflicting. ${ }^{18-20}$ Although these differences could be explained by variations in enteropathogenic $E$ coli pathogenicity, it seems more likely that some researchers were working with both enteropathogenic and enterotoxigenic $E$ coli, which at that time were not recognised as separate entities that cause diarrhoea by distinctive mechanisms and therefore produce different pathological effects. Failure to distinguish between $E$ coli of different pathogenic groups may also account for some of the contradictory reports of the pathology of $E$ coli diarrhoea in children, in whom findings ranging from normal ${ }^{2122}$ to extremely severe, with intestinal perforation and gangrene, ${ }^{23}{ }^{24}$ have been described. The range of intestinal pathology found at necropsy of neonates suggested to Rho et al that host rather than bacterial factors influenced the course of infection more strongly. ${ }^{25}$ Another explanation is that enteropathogenic $E$ coli comprise a heterogeneous collection of bacteria lacking easily identifiable virulence characteristics. The finding that enteropathogenic $E$ coli strains of different serotypes and of diverse origin produced similar pathological changes in experimental animals indicates, however, that different enteropathogenic $E$ coli strains probably produce enteritis by the same mechanism.

Notwithstanding the reported variations in enteropathogenic $E$ coli-associated pathology, light microscopic examination of the intestine of most children with enteropathogenic $E$ coli-induced diarrhoea shows infiltration of the mucosa and submucosa by polymorphonuclear leucocytes, plasma cells, and macrophages, accompanied by varying degrees of oedema and capillary congestion. ${ }^{13} 24-26$ This picture resembles that seen in experimentally infected piglets.

Recent electron microscopic studies of enteropathogenic $E$ coli-induced changes in experimental and naturally occurring infections have provided a more coherent picture of enteropathogenic $E$ coli enteritis. In independent studies of human enteropathogenic $E$ coli infection of rabbits, Polotsky et $a l^{27}$ and Prescott ${ }^{28}$ reported ultrastructural changes in enterocytes, including microvillous degeneration, and cupping and pedestal formation, similar to those found in piglets in the present study. These changes also characterise the disease in naturally infected children ${ }^{1326}$ and in rabbits infected with $E$ coli RDEC-1, a non-enterotoxigenic, naturallyoccurring rabbit pathogen. ${ }^{29}{ }^{30}$ Recently, Moon et $a l,{ }^{3}$ have shown that strain RDEC-1 and several human enteropathogenic $E$ coli strains give rise to similar light and electron microscopic changes in gnotobiotic piglets and in rabbit and piglet ligated ileal loops.

Our findings agree largely with those of Moon $e t$ $a l,{ }^{3}$ except that we found considerably less animal-to-animal variation in response to each enteropathogenic $E$ coli strain than that reported by Moon's group. ${ }^{3}$ This apparent conflict can be explained by the fact that, in our study, piglets inoculated with each enteropathogenic $E$ coli strain were litter mates, given a measured bacterial inoculum, reared together under identical conditions and necropsied at specified time intervals. It is noteworthy, however, that different enteropathogenic $E$ coli strains, including some of the same serotype - for example, E508/69 and $\mathrm{E} 2347 / 69$, both of which are $0114: \mathrm{H} 2$, produced clinical and pathological changes of varying severity. Whether this disparity reflects differences in the inherent pathogenicity of different enteropathogenic $E$ coli or variations in host susceptibility remains uncertain.

The close resemblance of enteropathogenic $E$ coli-induced changes in piglets to those reported in naturally infected humans and rabbits indicates that gnotobiotic piglets are a useful model of human disease. Equally striking was the finding that the relative pathogenicity of human 
enteropathogenic $E$ coli for piglets corresponded to the pathogenicity of the same strains in adult volunteers. ${ }^{14}$

A possible drawback of the gnotobiotic piglet model, apart from its lack of general availability, is that diarrhoea did not always occur in animals infected with enteropathogenic $E$ coli. This may be explained by the fact that, in neonatal piglets, most absorption of fluid and electrolytes takes place in the proximal small intestine, whereas most enteropathogenic $E$ coli-induced pathology occurred in the terminal ileum and colon. This explanation is supported by the finding that those enteropathogenic $E$ coli strains which caused diarrhoea generally colonised the small intestine more extensively and gave rise to more severe and widespread pathological changes in the intestine than strains that did not cause diarrhoea. It is also possible, however, that diarrhoeagenic enteropathogenic $E$ coli may possess virulence factors, such as enterotoxins, in addition to those necessary for adherence and the production of tissue damage.

In summary, this report documents the usefulness of gnotobiotic piglets as a model for enteropathogenic $E$ coli enteritis. Support for this conclusion stems from (i) the similar clinical signs in piglets and humans infected with enteropathogenic $E$ coli, apart from the absence of diarrhoea in some experimental animals; (ii) the similar light and electron microscopic observations in experimental and naturally occurring enteropathogenic $E$ coli infections; (iii) the similar bacterial colonisation of the small intestine as revealed by culture and PAP staining; (iv) the occurrence of brush border damage and reduced lactase activity in experimentally infected piglets and naturally infected children, ${ }^{1326}$ and (v) the corresponding severity of enteropathogenic $E$ coli-induced disease in piglets and adult volunteers. The specificity of the piglet model was further shown by the failure of an avirulent normal flora $E$ coli to induce any morphological or functional abnormalities in infected animals.

The availability of the piglet model will enable investigation of the pathogenic mechanisms of enteropathogenic $E$ coli, including the relative contribution of adhesion, invasive ability and enterotoxigenicity to virulence. Recently, piglets were used to investigate the role of plasmids in enteropathogenic $E$ coli pathogenicity. ${ }^{11}$ It will now also be possible to examine factors influencing the immunity to and recovery from enteropathogenic $E$ coli disease so that effective means of treating and preventing this condition may be developed.
We are grateful to Drs S B Formal, Washington DC, USA; M M Levine, Baltimore MD, USA, and $B$ Rowe, Colindale, London, UK, for providing the bacteria used in this investigation, and to Robyn Anderson, Judy Cram, Liz Robinson, and Karen Wilson for technical assistance. The gnotobiotic pig unit is funded in part by the Australian Pig Industry Research Committee.

\section{References}

1 Rowe B. The role of Escherichia coli in diarrhoea. Clin Gastroenterol 1979; 8: 625-44.

2 Sack RB. Enterotoxigenic Escherichia coli: identification and characterization. $J$ Infect Dis 1980; 142: 279-86.

3 Moon HW, Whipp SC, Argenzio RA, Levine MM, Gianella RA. Attaching and effacing activities of rabbit and human enteropathogenic Escherichia coli in pig and rabbit intestines. Infect Immun 1983; 41: 1340-51.

4 Neter E. Enteritis due to enteropathogenic Escherichia coli. Am J Dig Dis 1965; 10: 883-6.

5 Robins-Browne RM. Seasonal and racial incidence of infantile gastroenteritis in South Africa. Am J Epidemiol 1984; 119: 350-5.

6 Robins-Browne RM, Levine MM, Rowe B, Gabriel EM. Failure to detect conventional enterotoxins in classical enteropathogenic (serotyped) Escherichia coli strains of proven pathogenicity. Infect Immun 1982; 38: 798-801.

7 Edelman R, Levine MM. Summary of a workshop on enteropathogenic Escherichia coli. J Infect Dis 1983; 147: 1108-18.

8 Tzipori S, Chandler D, Smith M, Makin T, Halpin C. Experimental colibacillosis in gnotobiotic piglets exposed to 3 enterotoxigenic serotypes. Aust Vet J 1982; 59: $93-5$.

9 Tzipori SR, Makin TJ, Smith ML. The clinical response of gnotobiotic calves, pigs and lambs to inoculation with human, calf, pig and foal rotavirus isolates. Aust J Exp Biol Med 1980; 58: 309-18.

10 Tzipori S. Cryptosporidiosis in animals and humans. Microbiol Rev 1983; 47: 84-96.

11 Baldini MM, Kaper JB, Levine MM, Candy DCA, Moon HW. Plasmid-mediated adhesion in enteropathogenic Escherichia coli. J Pediatr Gastroenterol Nutr 1983; 2: 534-8.

12 Gross RJ, Scotland SM, Rowe B. Enterotoxin testing of Escherichia coli causing epidemic infantile enteritis in the U.K. Lancet 1976; 1: 629-31.

13 Ulshen MH, Rollo JL. Pathogenesis of Escherichia coli gastroenteritis in man - another mechanism. $N$ Engl J Med 1980; 302: 99-101.

14 Levine MM, Bergquist EJ, Nalin DR et al. Escherichia coli strains that cause diarrhoea but do not produce heat-labile or heat-stable enterotoxins and are non-invasive. Lancet 1978; 1: 1119-22. 
15 Makin TJ, Tzipori S. Inexpensive techniques for the production and maintenance of gnotobiotic piglets, calves and lambs. Aust Vet $J$ 1980; 56: 353-8.

16 Taylor CR. Immunoperoxidase techniques: practical and theoretical aspects. Arch Pathol Lab Med 1978; 102: 113-21.

17 Dahlquist A. Method for assay of intestinal disaccharidases. Anal Biochem 1964; 7: 18-25.

18 De SN, Bhattacharya K, Sarker JK. A study of the pathogenicity of strains of Bacterium coli from acute and chronic enteritis. J Pathol Bacteriol 1956; 71: 201-9.

19 McNaught W, Roberts GBS. Enteropathogenic effects of strains of Bacterium coli isolated from cases of gastroenteritis. J Pathol Bacteriol 1958; 76: 155-8.

20 Taylor J, Maltby MP, Payne JM. Factors influencing the response of ligated rabbit-gut segments to injected Escherichia coli. J Pathol Bacteriol 1958; 76: 491-9.

21 Modica RI, Ferguson WW, Ducey EF. Epidemic infantile diarrhea associated with Escherichia coli 111, B4. J Lab Clin Med 1952; 39: 122-8.

22 Kessner DM, Saugnessy HJ, Googins J, Rasmussen $\mathrm{CM}$ et al. An extensive community outbreak of diarrhea due to enteropathogenic Escherichia coli 0111: B4. I. Epidemiologic studies. Am J Hyg 1962; 76: 27-43.

23 McKay DG, Wahle GH Jr. Epidemic gastroenteritis due to Escherichia coli 0111 B4. II. Pathologic anat- omy (with special reference to the presence of the local and generalized Shwartzman phenomena). Arch Pathol 1955; 60: 679-93.

24 Drucker MM, Polliack A, Yeivin R, Sacks TG. Immunofluorescent demonstration of enteropathogenic Escherichia coli in tissues of infants dying with enteritis. Pediatrics 1970; 46: 855-64.

25 Rho Y-M, Josephson JE. Epidemic enteropathogenic Escherichia coli, Newfoundland, 1963: autopsy study of 16 cases. Canad Med Ass J 1967; 96: 392-8.

26 Rothbaum R, McAdams AJ, Gianella R, Partin JC. A clinicopathologic study of enterocyte-adherent Escherichia coli: a cause of protracted diarrhea in infants. Gastroenterology 1982; 83: 441-54.

27 Polotsky YE, Dragunskaya EM, Seliverstova VB et al. Pathogenic effect of enterotoxigenic Escherichia coli and Escherichia coli causing infantile diarrhoea. Acta Microbiol Acad Sci Hung 1977; 24: 221-36.

28 Prescott JF. Escherichia coli and diarrhoea in the rabbit. Vet Pathol 1978; 15: 237-48.

29 Cantey JR, Blake RK. Diarrhea due to Escherichia coli in the rabbit. A novel mechanism. J Infect Dis 1977; 135: 454-62.

30 Takeuchi A, Inman LR, O'Hanley PD, Cantey JR, Lushbaugh WB. Scanning and transmission electron microscopic study of Escherichia coli 015 (RDEC-1) enteric infection in rabbits. Infect Immun 1978; 19: 686-94 